\title{
Evaluating influenza disease burden during the 2008-2009 and 2009-2010 influenza seasons in Mongolia
}

Nao Nukiwa a Alexanderyn Burmaa b Taro Kamigaki a Badarchiin Darmaa b ligiidsurengiin Od c Ishiin Odd Bagtaryn

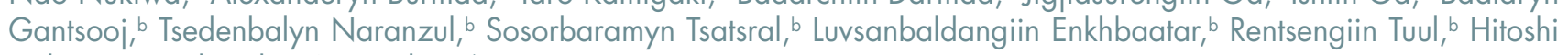
Oshitani, ${ }^{a}$ Pagbajabyn Nymadawa ${ }^{b}$

Correspondence to Pagbajabyn Nymadawa (e-mail: nymadawa@gmail.com)

It is critical to monitor the incidence and clinical characteristics of influenza and its associated hospitalization to understand influenza disease burden. A disease burden study can inform the prioritization of a public health response. However, little is known about the epidemiology and disease burden of influenza in developing countries, including Mongolia. Thus we performed prospective data and sample collection from patients who visited outpatient clinics with influenza-like illness (ILI) and hospitalized patients with severe acute respiratory infections (SARI) in two sites of Mongolia, Baganuur District of Ulaanbaatar and Selenghe Province, from 2008 to 2010. In total, we examined 350 ILI cases during the 2008-2009 influenza epidemic period and 1723 ILI cases during the 2009-2010 influenza epidemic period.

We observed the highest ILI incidence per 1000 population in the one to four year age group in Baganuur and in the under one year age group in Selenghe during both periods. Thirteen SARI cases were positive for seasonal influenza A(H1N1) during the 2008-2009 season and 17 SARI cases were positive for pandemic influenza A(H1N1) 2009 during the 2009-2010 season. Among these cases, $84.6 \%$ and 58.8\% were children under five years of age, respectively, during the 2008-2009 and 2009-2010 seasons. Taken together, children, especially children under five years, had higher influenza infection incidence and hospitalization rate in Mongolia. Although mortality impact also should be considered, we believe that our findings can be useful in formulating an influenza control strategy during influenza epidemic periods in Mongolia.

I nfluenza is a common vaccine-preventable viral infection that is characterized by a sudden onset of fever, headache, myalgia, malaise, non-productive cough, sore throat and rhinitis. Influenza can cause severe disease or death in the very young, the elderly and people with underlying medical conditions. In developed countries with temperate climates, annual seasonal epidemics usually occur in winter or early spring and often result in dramatic increases incases, hospitalizations and deaths. The methods used to estimate disease burden, especially mortality impact, have been well established in developed countries and several such study results have been published. ${ }^{1-5}$ On the other hand, much less is known about the burden of influenza in developing countries. Monitoring the incidence and clinical characteristics of influenza and hospitalization due to influenza is critical in understanding the influenza disease burden in the population and guiding prevention and control strategies.
Mongolia is a landlocked, middle-income country in north-eastern Asia. Mongolia's total land area is $1566600 \mathrm{~km}^{2}$ and its population density was 1.7 people per square kilometre in 2008 . The average annual rainfall is low $(200-220 \mathrm{~mm}$ ) with the heaviest rainfall between June and August. In 2008, the total population of Mongolia was estimated to be 2694955 , with $27.6 \%$ of the population under 15 years of age, $68.3 \%$ in the $15-64$ year age group and $4.1 \%$ aged 65 years and older.

Little is known about the influenza disease burden in Mongolia. ${ }^{6-8}$ Therefore, we performed prospective data and sample collection from patients who visited outpatient clinics with influenza-like illness (ILI) and hospitalized patients with severe acute respiratory infections (SARI) to define the epidemiology and disease burden of influenza in Mongolia.

\footnotetext{
a Department of Virology, Tohoku University Graduate School of Medicine, Sendai, Japan

b National Influenza Center, National Center of Communicable Diseases, Ulaanbaatar, Mongolia

c Health Department, Selenghe Province, Mongolia

d Baganuur District, Ulaanbaatar, Mongolia

Submission date: 16 September 2010; Publication date: 18 January 2011

doi: 10.5365/wpsar.2010.1.1.004
} 


\section{Figure 1. Map of study sites in Mongolia}

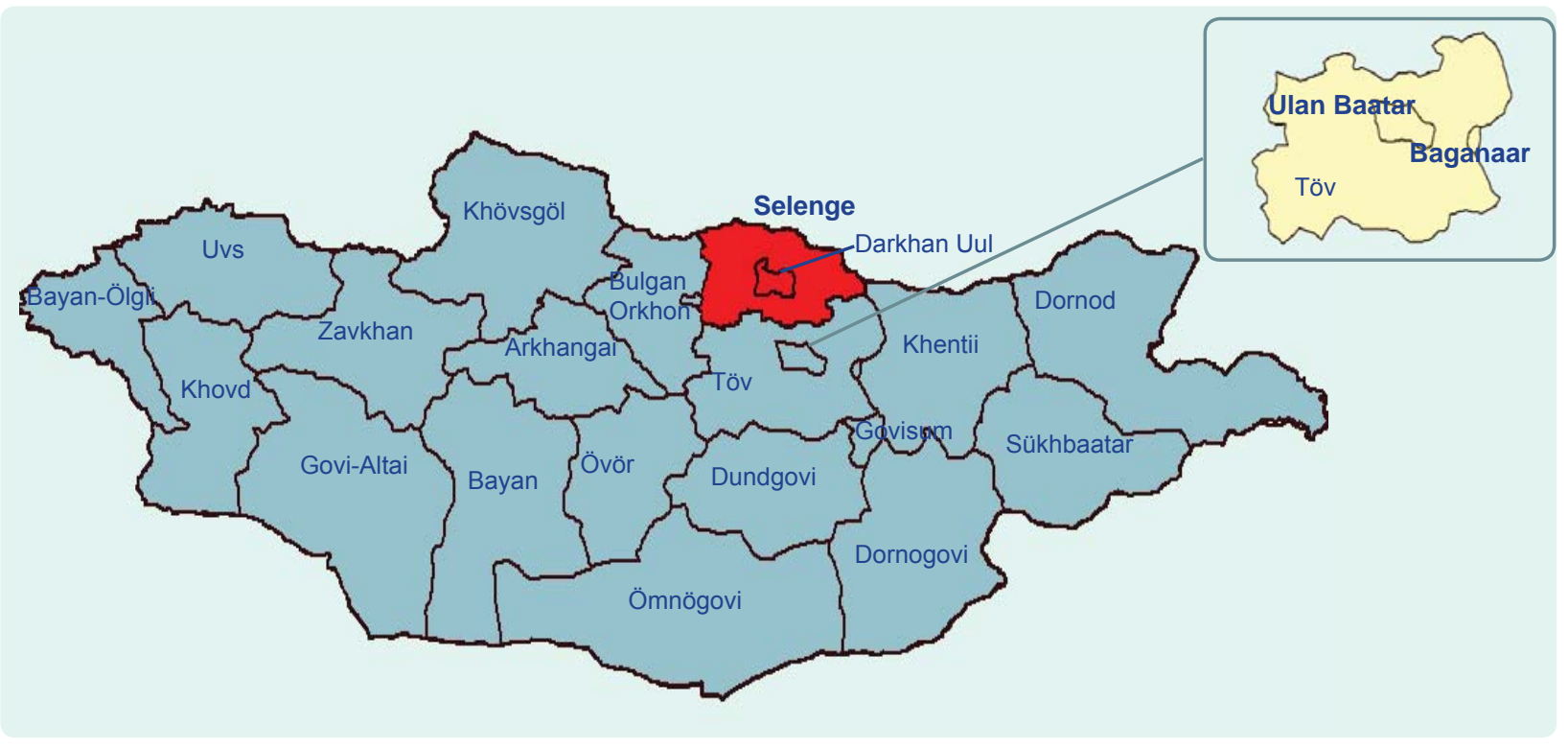

\section{METHODS}

We selected the study population and conducted health care facility-based surveillance to monitor the incidence of ILI and hospitalization with SARI during the 2008-2009 and 2009-2010 influenza seasons. Two study sites were chosen. One site was Baganuur District, a district of Ulaanbaatar, the capital of Mongolia, located $130 \mathrm{~km}$ east of the city centre with a population of 25875 . The other study site was Selenghe Province, located $300 \mathrm{~km}$ north of Ulaanbaatar at the border to the Russian Federation with a population of 21460 (Figure 1). Age distribution nationwide and at the two study sites were comparable (Table 1). Each site has one hospital and four family group practices (outpatient clinics), and all the residents receive free medical care. All the patients with ILI who visited these health care facilities as well as patients who were hospitalized with a diagnosis of SARI were enrolled in this study.

An ILI case was defined as a person with sudden onset of fever $\left(>38.0^{\circ} \mathrm{C}\right)$ and cough or sore throat in the absence of other diagnoses. A SARI case was defined as a person with ILI who developed shortness of breath or difficulty breathing and required hospital admission. Nasopharyngeal swabs were collected for virological testing from patients who met the case definitions of ILI or SARI and whose onset of symptoms were within 72 hours. We collected a maximum of 20 swabs per week from each study site. The specimens were transported to and tested at the National Influenza Center, National Center of Communicable Diseases laboratory in Ulaanbaatar. Real-time reverse transcriptase polymerase chain reaction (RT-PCR) was used to detect influenza

Table 1. Population by age group

\begin{tabular}{|c|c|c|c|}
\hline & Nationwide & Baganuur & Selenghe \\
\hline 0-11 months & $64074 \quad(2 \%)$ & $671(3 \%)$ & $356 \quad(2 \%)$ \\
\hline $1-4$ years & $197046(7 \%)$ & $1721(7 \%)$ & 1392 (6\%) \\
\hline 5-9 years & 231309 (9\%) & $2180 \quad(8 \%)$ & 1919 (9\%) \\
\hline $10-14$ years & 251864 (9\%) & $2528(10 \%)$ & 1952 (9\%) \\
\hline $15-24$ years & $579274(22 \%)$ & $5911(23 \%)$ & 4609 (21\%) \\
\hline $25-44$ years & $860574(32 \%)$ & $8101(31 \%)$ & $6830(32 \%)$ \\
\hline $45-64$ years & $401437(15 \%)$ & $3700(14 \%)$ & 3591 (17\%) \\
\hline$\geq 65$ years & $109377(4 \%)$ & $1063(4 \%)$ & 811 (4\%) \\
\hline Total & 2694955 & 25875 & 21460 \\
\hline
\end{tabular}


Figure 2. Epidemiological curve of ILI cases and the proportion of specimens positive for influenza in Baganuur

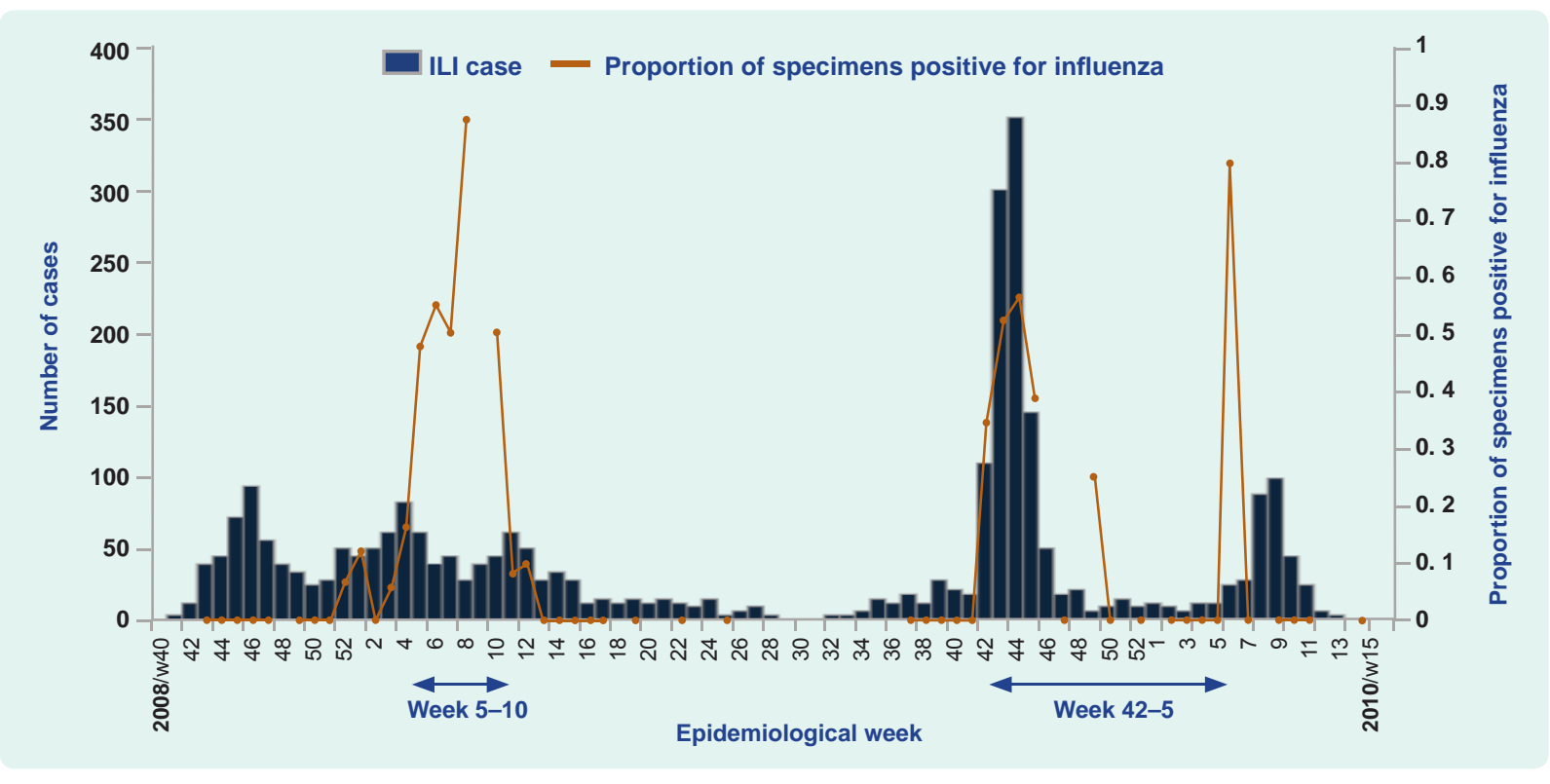

$A(H 1 N 1), \quad A(H 3 N 2)$ and $B$ with specific primers following the protocol provided by the Centers for Disease Control and Prevention in the United States of America. In addition, after the first pandemic influenza A(H1N1) 2009 case was confirmed in Mongolia (October 2009), pandemic influenza A(H1N1) 2009 virus was also detected by using real-time RT-PCR. ${ }^{9}$ The proportion of specimens positive for influenza virus was calculated for each week. For each influenza season, we defined the influenza epidemic period starting from the week when the proportion of specimens positive for influenza first reached $20 \%$ and ending when it fell below $20 \%$. Information on demographic characteristics; medical history, including underlying medical conditions; influenza immunization status; clinical course and treatment with antiviral medications was collected from every case by using a standardized questionnaire. The government census data in 2008 were used for estimating population-based proportion. Data were entered into a Microsoft Access database (Microsoft, WA, USA) and statistical analyses were conducted using SPSS version 18.1 (IBM, IL, USA).

Figure 3. Epidemiological curve of ILI cases and the proportion of specimens positive for influenza in Selenghe

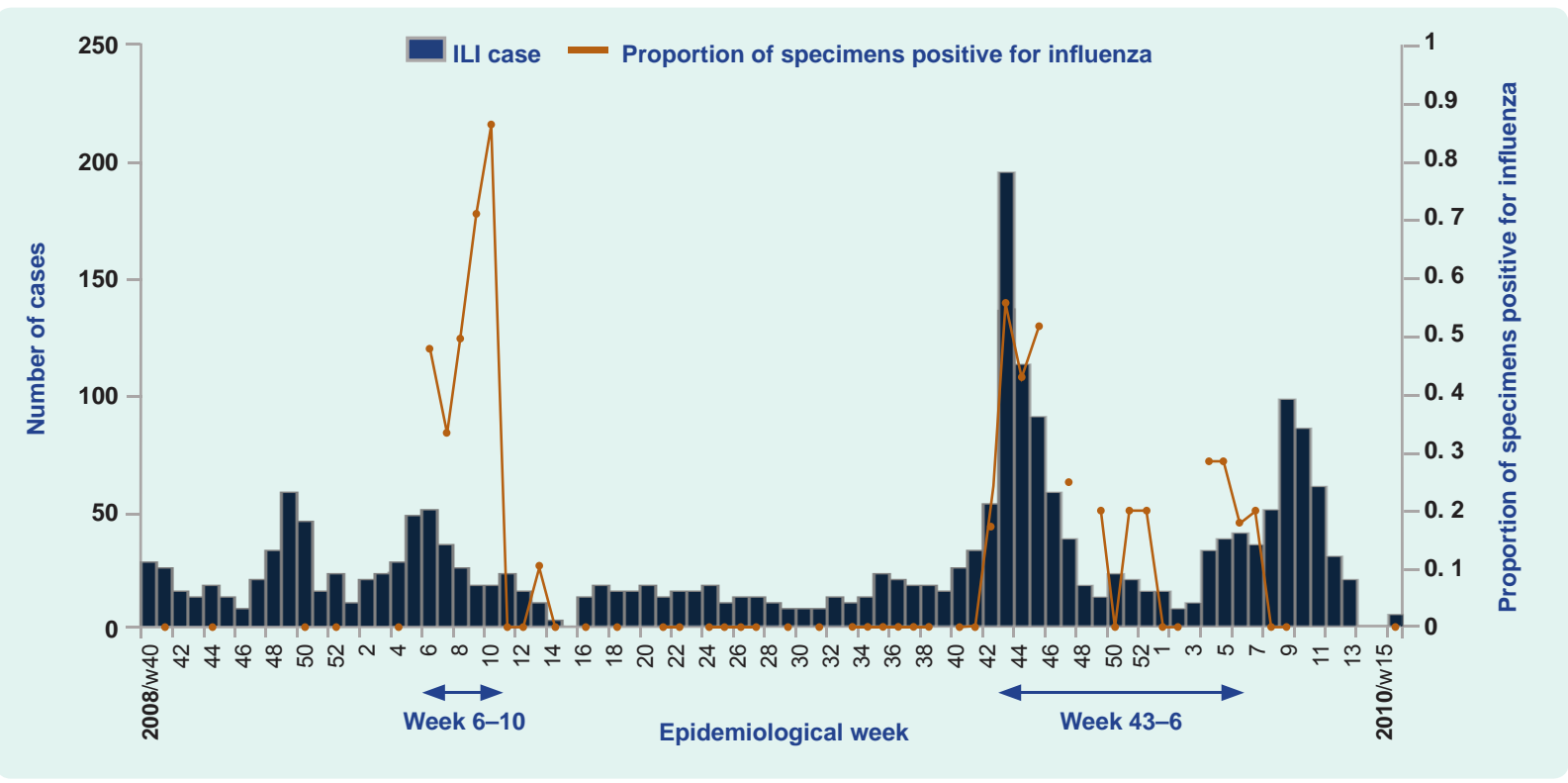


Table 2. Number of ILI cases and incidence per 1000 population in Baganuur during the two influenza epidemic periods

\begin{tabular}{lcccc}
\hline \multirow{2}{*}{ Age group } & \multicolumn{2}{c}{$\begin{array}{c}\text { 2008-2009 influenza period } \\
\text { Week 5, 2009-week 10, 2009 } \\
\text { (6 weeks) }\end{array}$} & \multicolumn{2}{c}{$\begin{array}{c}\text { 2009-2010 influenza period } \\
\text { Week 42, 2009-week 5, 2010 } \\
\text { (17 weeks) }\end{array}$} \\
\cline { 2 - 5 } & $\begin{array}{c}\text { Number of } \\
\text { ILI cases }\end{array}$ & $\begin{array}{c}\text { Incidence per 1000 } \\
\text { population }\end{array}$ & $\begin{array}{c}\text { Number of } \\
\text { ILI cases }\end{array}$ & $\begin{array}{c}\text { Incidence per 1000 } \\
\text { population }\end{array}$ \\
\hline 0-11 months & 18 & 2.7 & 54 & 8.0 \\
1-4 years & 79 & 4.6 & 221 & 12.8 \\
$5-9$ years & 55 & 2.5 & 177 & 8.1 \\
10-14 years & 25 & 1.0 & 194 & 7.7 \\
15-24 years & 23 & 0.4 & 160 & 2.7 \\
25-44 years & 17 & 0.2 & 164 & 2.0 \\
45-64 years & 5 & 0.1 & 71 & 1.9 \\
$\geq 65$ years & 3 & 0.3 & 25 & 2.4 \\
\hline Total & 225 & 0.9 & 1066 & 4.1 \\
\hline
\end{tabular}

\section{RESULTS}

This study was conducted from 1 October 2008 to 18 April 2010. In total, 128 samples (17\%) out of 733 collected samples in Baganuur District and 93 samples (18\%) out of 510 collected samples in Selenghe Province were positive for either seasonal influenza $A(H 1 N 1)$ or pandemic influenza $A(H 1 N 1)$ 2009 viruses (Figures 2, 3). Influenza $A(H 3 N 2)$ and $B$ viruses were not detected during the study period. There were several weeks during the pandemic in which we could not collect samples due to limited laboratory capacity. The influenza epidemic period of the 2008-2009 season in Baganuur ran from week five of 2009 through week 10 of 2009 (six weeks) and that of the 2009-2010 season ran from week 42 of 2009 though week five of 2010 (17 weeks) (Figure 2). Similarly, the influenza epidemic period of the 2008-2009 season in Selenghe ran from week six of 2009 through week 10 of 2009 (five weeks) and that of the 2009-2010 season ran from week 43 of
2009 through week six of 2010 (17 weeks) (Figure 3). We observed the demographic characteristics of ILI cases during these influenza epidemic periods.

\section{Influenza-like illness at each site}

In Baganuur, $225 \mathrm{ILI}$ cases were enrolled during the 2008-2009 influenza epidemic period and $1066 \mathrm{ILI}$ cases during the 2009-2010 influenza epidemic period (Table 2). The median age of cases was six years (range two months-81 years) during the 2008-2009 period and 12 years (range 22 days-85 years) during the 2009-2010 period. There was no difference in the male-to-female ratio between the two periods (0.9). One hundred and seventy-seven ILI cases (78.7\%) during the 2008-2009 period and 646 cases $(60.6 \%)$ during the 2009-2010 period were younger than 15 years of age. On the other hand, three cases (1.3\%) during the 2008-2009 period and 25 cases (2.3\%) during the 2009-2010 period were 65 years of age or older (Table 2). ILI incidence per 1000 population

Table 3. Number of ILI cases and incidence per 1000 population in Selenghe during the two influenza epidemic periods

\begin{tabular}{ccccc}
\hline \multirow{2}{*}{ Age group } & \multicolumn{2}{c}{$\begin{array}{c}\text { 2008-2009 influenza period } \\
\text { Week 6, 2009-week 10, 2009 } \\
\text { (5 weeks) }\end{array}$} & $\begin{array}{c}\text { 2009-2010 influenza period } \\
\text { Week 43, 2009-week 6, 2010 } \\
\text { (17 weeks) }\end{array}$ \\
\cline { 2 - 5 } & $\begin{array}{c}\text { Number of } \\
\text { ILI cases }\end{array}$ & $\begin{array}{c}\text { Incidence per 1000 } \\
\text { population }\end{array}$ & $\begin{array}{c}\text { Number of } \\
\text { ILI cases }\end{array}$ & $\begin{array}{c}\text { Incidence per 1000 } \\
\text { population }\end{array}$ \\
\hline 0-11 months & 13 & 3.7 & 78 & 21.9 \\
$1-4$ years & 39 & 2.8 & 157 & 11.3 \\
$5-9$ years & 26 & 1.4 & 108 & 5.6 \\
$10-14$ years & 20 & 1.0 & 82 & 4.2 \\
$15-24$ years & 14 & 0.3 & 112 & 2.4 \\
$25-44$ years & 9 & 0.1 & 92 & 1.3 \\
$45-64$ years & 4 & 0.1 & 22 & 0.6 \\
$\geq 65$ years & 0 & 0.0 & 6 & 0.7 \\
\hline Total & 125 & 0.6 & 657 & 3.1 \\
\hline
\end{tabular}


Table 4. Result of samples collected from SARI cases

\begin{tabular}{ccc}
\hline & $\begin{array}{c}\text { 2008-2009 } \\
\text { season }\end{array}$ & $\begin{array}{c}\text { 2009-2010 } \\
\text { season }\end{array}$ \\
\hline $\begin{array}{c}\text { Seasonal influenza } \\
\mathrm{A}(\mathrm{H} 1 \mathrm{~N} 1)\end{array}$ & 13 & 0 \\
$\begin{array}{c}\text { Pandemic influenza } \\
\mathrm{A}(\mathrm{H} 1 \mathrm{~N} 1) \text { 2009 }\end{array}$ & 0 & 17 \\
Negative & 96 & 39 \\
\hline Total sample tested & 109 & 56 \\
\hline
\end{tabular}

by each age group is shown in Table 2. The highest incidence was seen in the one to four year age group during both influenza epidemic periods. The ratio of ILI incidence between the 2008-2009 and 2009-2010 periods was highest (14.2) among the 45-64 year age group.

In Selenghe, $125 \mathrm{ILI}$ cases were enrolled during the 2008-2009 influenza epidemic period and $657 \mathrm{ILI}$ cases during the 2009-2010 influenza epidemic period (Table 3 ). The median age was seven years (range one month-63 years) during the 2008-2009 period and eight years (range 23 days-78 years) during the 2009-2010 period. The male-to-female ratio was 0.6 and 0.9 for the 2008-2009 and 2009-2010 periods, respectively, indicating more females presented with ILI during the 2008-2009 period. Ninety-eight ILI cases (78.4\%) during the 2008-2009 period and $425 \mathrm{ILI}$ cases $(64.7 \%)$ during the $2009-2010$ period were younger than 15 years of age. On the other hand, no case during the 2008-2009 period and six cases $(0.9 \%)$ during the 2009-2010 period were 65 years of age or older (Table 3). ILI incidence per 1000 population by each age group is shown in Table 3 .
Table 5. Age distribution of SARI cases confirmed with influenza virus

\begin{tabular}{lcc}
\hline & $\begin{array}{c}\text { 2008-2009 } \\
\text { season }\end{array}$ & $\begin{array}{c}\text { 2009-2010 } \\
\text { season }\end{array}$ \\
\hline 0-11 months & 4 & 1 \\
1-4 years & 7 & 9 \\
5-9 years & 1 & 0 \\
10-14 years & 0 & 3 \\
15-24 years & 1 & 4 \\
25-44 years & 0 & 0 \\
45-64 years & 0 & 0 \\
$\geq 65$ years & 0 & 0 \\
\hline Total & 13 & 17 \\
\hline
\end{tabular}

The highest incidence was seen in children under one year old during both influenza epidemic periods. The ratio of ILI incidence between the 2008-2009 and 2009-2010 periods was highest (10.2) among the 25-44 year age group.

\section{Severe acute respiratory infections with influenza}

In total, 165 SARI cases were tested for influenza during the study period. Thirteen cases were positive for seasonal influenza $A(H 1 N 1)$ virus during the 2008-2009 season, and 17 cases were positive for pandemic influenza $A(H 1 N 1) 2009$ virus during the 2009-2010 season (Table 4). Further analysis was focused on those influenza-positive cases. The median age of SARI cases during the 2008-2009 season was one year (range one month-20 years) while that of the 2009-2010 season was four years (range six months22 years). Among SARI cases, $84.6 \%$ and $58.8 \%$ were younger than five years of age during the 2008-2009 and 2009-2010 seasons, respectively (Table 5).

Table 6. Characteristics of influenza-positive SARI cases and their clinical course

\begin{tabular}{|c|c|c|}
\hline & $\begin{array}{l}\text { 2008-2009 season } \\
(n=13)\end{array}$ & $\begin{array}{c}2009-2010 \text { season } \\
(n=17)\end{array}$ \\
\hline $\begin{array}{l}\text { Median age } \\
\quad \text { (range) }\end{array}$ & $\begin{array}{c}1 \text { year } \\
\text { (1 month-20 years) }\end{array}$ & $\begin{array}{c}4 \text { years } \\
\text { (6 months-22 years) }\end{array}$ \\
\hline Male-to-female ratio & 0.9 & 0.8 \\
\hline Underlying medical conditions & 2 cases & 3 cases \\
\hline Antiviral treatment & 0 cases & 5 cases \\
\hline Oxygen supply & 0 cases & 3 cases \\
\hline Ventilation support & 1 case & 0 cases \\
\hline $\begin{array}{l}\text { Mean duration between onset and } \\
\text { admission }\end{array}$ & 5.5 days & 5.2 days \\
\hline Mean hospitalization period & 7.2 days & 5.8 days \\
\hline
\end{tabular}


The characteristics of influenza-positive SARI cases and their clinical course are shown in Table 6. SARI patients during the pandemic period were more likely to be older and female. Two (15.4\%) patients during the 2008-2009 season and four (23.5\%) patients during the 2009-2010 season had underlying medical conditions. None of the hospitalized patients had influenza vaccination in either season. Mean duration between onset of illness to admission was similar for the two seasons. Five out of 17 cases $(29.4 \%)$ were administered antiviral treatments during the 2009-2010 season, while none was given during the 2008-2009 season. Three cases received oxygen supply during the 2009-2010 season, and ventilation support was provided to one case during the 2008-2009 season. The mean length of hospital stay was longer during the 2008-2009 season compared with the 2009-2010 season ( 7.2 days versus 5.8 days). No fatal case was observed during either season.

\section{DISCUSSION}

In temperate countries, influenza activity has a clear seasonality. Mongolia is located in a temperate zone of north-eastern Asia and therefore has clear seasonal patterns of influenza, as evidenced through national influenza surveillance. ${ }^{7}$ However, no apparent excess mortality was estimated by using the Serfling model. ${ }^{10}$ This may partly be because the elderly population, which occupies a major part of influenza excess mortality, is smaller in developing countries. Therefore, in this study, we conducted prospective surveillance and sample collection to define the influenza disease burden by focusing on outpatient visits with ILI and hospitalized patients with SARI.

In this study, we estimated ILI incidence in the 2008-2009 and 2009-2010 seasons and also characterized SARI cases. The highest ILI incidence was seen in children younger than five years of age and the same was seen among the influenza $A(H 1 N 1)$ positive SARI cases. Similar findings were observed in another influenza epidemiological study. ${ }^{11}$ The first confirmed case of pandemic influenza A(H1N1) 2009 virus in Mongolia was reported on 12 October 2009. Though the highest ILI incidence was observed among children younger than five years of age in both influenza epidemic periods, the ratio of ILI incidence between the 2008-2009 and 2009-2010 periods was highest among the age groups of 45-64 years (14.2) in Baganuur and 25-44 years (10.2) in Selenghe. This indicated that
ILI incidence among the adult population was elevated compared with the previous season. This might be due to the larger susceptible population that could result in a higher number of ILI, but it could also be due to the change of health-seeking behaviour because of the publicity during the 2009-2010 influenza epidemic period when the pandemic influenza $A(H 1 N 1) 2009$ virus was the dominant strain. Although very few vaccinations were administrated in these seasons and antiviral treatment was only administered during the pandemic period, no death was recorded and the number of confirmed SARI cases remained stable during the study period. Lower ILI incidence in the elderly population may explain why the severity of SARI due to influenza was low in Mongolia; however, we definitely need further studies since the size of registered SARI cases was small.

There are several limitations in our study. Because of limited laboratory capacity, especially during the pandemic period, we could not collect samples for certain weeks from all the ILI and SARI cases, which potentially led to an underestimation in the analysis. Because we defined the influenza epidemic periods from limited laboratory results and defined a cutoff point at $20 \%$ of influenza-positive proportion, we might have shortened the influenza epidemic periods and in turn underestimated the ILI cases. In spite of these limitations, the proportion of specimens positive for influenza in our study were $17 \%$ in Baganuur and $18 \%$ in Selenghe, which is compatible with other studies showing $10 \%-19 \%{ }^{12-14}$

We observed the highest incidence of ILI among children, especially children under five years of age; the highest proportion of SARI was also observed in this age group. Other infections such as respiratory syncytial virus and rhinovirus can also cause ILI in this age group, so it is necessary to examine other pathogens with influenza-negative samples for more clear disease burden estimation. We believe our findings can lead to awareness among parents who have young children with high potential to be affected with influenza infection. This awareness will encourage individuals in Mongolia to adopt non-pharmaceutical interventions (e.g. hand hygiene) during the influenza epidemic period. However, to reveal a more accurate disease burden of influenza in Mongolia and to develop intervention strategies such as a vaccination programme, further studies in urban areas and with more severe patients are necessary to observe the severity of influenza infection. 


\section{Conflicts of Interest:}

None declared.

\section{Funding:}

The surveillance part of the study was financially supported by the US/Mongolia Cooperative Agreement Project U50/CCU024411 "Development of Influenza Surveillance network" for which authors express their thanks.

\section{Acknowledgements}

The authors thank the doctors and assistants in the territorial hospitals and FGPs in Baganuur District, Ulaanbaatar City and Selenghe Province for collecting data and samples from the cases. The authors are also indebted to the assistants in the National Influenza Center, National Center of Communicable Diseases for entering data into the database.

\section{References:}

1. Serfling RE, Sherman IL, Houseworth WJ. Excess pneumoniainfluenza mortality by age and sex in three major influenza A2 epidemics, United States, 1957-58, 1960 and 1963. American Journal of Epidemiology, 1967, 86:433-441. pmid:6058395

2. Thompson WW, Comanor L, Shay DK. Epidemiology of seasonal influenza: use of surveillance data and statistical models to estimate the burden of disease. The Journal of Infectious Diseases, 2006, 194 Suppl 2: S82-91. doi:10.1086/507558 pmid:17163394

3. Choi K, Thacker SB. An evaluation of influenza mortality surveillance, 1962-1979. II. Percentage of pneumonia and influenza deaths as an indicator of influenza activity. American Journal of Epidemiology, 1981, 113:227-235. pmid:6258427
4. Chiu SS et al. Influenza-related hospitalizations among children in Hong Kong. The New England Journal of Medicine, 2002, 347:2097-2103. doi:10.1056/ NEJMoa020546 pmid:12501221

5. Assaad F, Cockburn WC, Sundaresan TK. Use of excess mortality from respiratory diseases in the study of influenza. Bulletin of the World Health Organization, 1973, 49:219-233. pmid: 4546520

6. Anchlan D et al. Previous H1N1 influenza A viruses circulating in the Mongolian population. Archives of Virology, 1996, 141:15531569. doi:10.1007/BF01718254 pmid:8856033

7. Tang JW et al. Comparison of the incidence of influenza in relation to climate factors during 2000-2007 in five countries. Journal of Medical Virology, 2010, 82:1958-1965. doi:10.1002/ jmv.21892 pmid:20872724

8. Hampson AW. Epidemiological data on influenza in Asian countries. Vaccine, 1999, 17 Suppl 1:S19-23. doi:10.1016/ S0264-410X(99)00100-0 pmid:10471175

9. CDC protocol of realtime RTPCR for influenza $A(H 1 N 1)$. Atlanta, Centers for Disease Control and Prevention, Updated 2009 Oct 6; cited 2009 Apr 28. (http://www.who.int/csr/resources/publications/ swineflu/CDCRealtimeRTPCR_SwineH1Assay-2009_20090430. pdf, accessed 26 October 2010).

10. Alexander B et al. Influenza related excess mortality estimates among all cause deaths in Mongolia, 2004-2007. International Journal of Infectious Diseases, 2008, 12 Supplement 1:e90. doi:10.1016/j.ijid.2008.05.225

11. Lemaitre M, Carrat F. Comparative age distribution of influenza morbidity and mortality during seasonal influenza epidemics and the 2009 H1N1 pandemic. BMC Infectious Diseases, 2010, 10:162. doi:10.1186/1471-2334-10-162 pmid:20534113

12. Mardy $S$ et al. Influenza activity in Cambodia during 2006-2008. BMC Infectious Diseases, 2009, 9:168. doi:10.1186/14712334-9-168 pmid:19828051

13. Nguyen HT et al. Vietnam National Influenza Surveillance and Evaluation Team. National influenza surveillance in Vietnam, 2006-2007. Vaccine, 2009, 28:398-402. doi:10.1016/j. vaccine.2009.09.139 pmid:19853073

14. Zaman RU et al. Influenza in outpatient ILI case-patients in national hospital-based surveillance, Bangladesh, 2007-2008. PLOS ONE, 2009, 4:e8452. doi:10.1371/journal.pone.0008452 pmid:20041114 